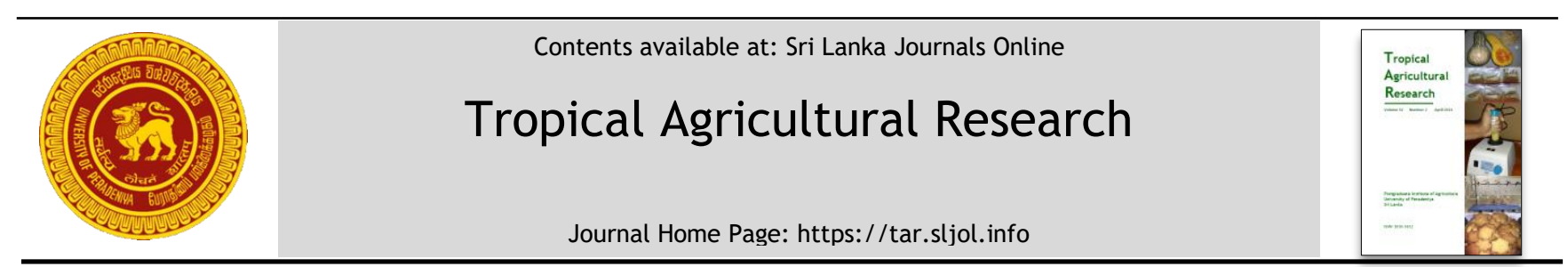

\title{
Use of Weather Information by Sri Lankan Paddy Farmers: An Application of Theory of Planned Behaviour
}

\author{
N.M.K.C. Premarathne ${ }^{1 *}$ A. Senaratne ${ }^{2}$ and L.H.P. Gunaratne ${ }^{3}$ \\ ${ }^{1}$ Department of Agricultural Systems, Faculty of Agriculture, Rajarata University of Sri Lanka, Puliyankulama, \\ Anuradhapura, Sri Lanka. \\ 2 Institute of Policy Studies of Sri Lanka, Colombo 07, Sri Lanka. \\ 3 Department of Agricultural Economics and Business Management, Faculty of Agriculture, University of Peradeniya, \\ Peradeniya, Sri Lanka.
}

\section{ARTICLE INFO}

\section{Article history:}

Received: 30 July 2020

Revised version received: 31 October 2020

Accepted: 17 January 2021

Available online: 1 April 2021

\section{Keywords:}

Paddy farmers

Planned behaviour

Structural equation model

Weather Information

\section{Citation:}

Premarathne, N.M.K.C., Senaratne, A. and Gunaratne, L.H.P. (2021). Weather Information Use of Sri Lankan Paddy Farmers: An Application of Theory of Planned Behaviour. Tropical Agricultural Research, 32(2): 155-167.

DOI: http://doi.org/10.4038/tar.v32i2.8463

Premarathne, N.M.K.C.

https://orcid.org/0000-0001-6070-7399.

\section{ABSTRACT}

Use of weather information by the Sri Lankan farmers is based on two information sources: traditional knowledge and agromet advisories provided by the Department of Meteorology through the Department of Agriculture. In this context the weather information use behaviour of Sri Lankan paddy farmers was investigated by using the theory of planned behaviour. The necessary data were collected through a pretested structured questionnaire administered with a multi-stage random sample of 900 farmers representing six districts in Sri Lanka. Two structural equation models (SEM) were built with respect to the two information systems. For both SEMs, the use frequency of information was considered as the behaviour, while subjective norm, perceived behaviour control, attitude and intention were considered as the behaviour specific beliefs. The structural validity of the questions and sample adequacy were separately checked for both SEM models. Results of the two SEM models showed significant $(\mathrm{p}<0.05)$ relationships for (1) attitude and intention, (2) attitude and behaviour, (3) subjective norm and intention, (4) perceived behavioural control and intention, and (5) intention and behaviour. It was revealed that the behavioural beliefs are important to determine the use of information systems. Therefore, the correct intervention is required to change or improve the existing behavioural beliefs when promoting weather information systems which are specifically designed against future climate turbulences.

*Corresponding author: nmkapila@yahoo.com 


\section{INTRODUCTION}

Farmers throughout the history used to foretell the future climate and weather events. These include, appearance of some animals, sounds of some specific animals, presence of some conditions like heat or cold, and flowering of trees. Such observations and experience, have been accumulated as local knowledge which transferred from generation to generation (Luseno et al., 2003; Stigter et al., 2005; Orlove et al., 2010). Later, the scientific weather forecasting was introduced to support the farming decisions (Salinger et al., 2000). The integrative uses of the modern and traditional knowledge of weather forecasts have been observed in almost all agricultural regions in the world (Nyong, 2007; Kalanda et al., 2011). Today, with the concerns on anticipated climate change, demand for precise forecasts increased unprecedented manner to support the climate change adaptation (Ensor and Berger, 2009; Giorgi et al., 2009).

Sri Lankan farmers have a traditional weather forecast system (Wagachchi and Wiersum, 1996; Senanayake , 2006; Berger et al., 2009). It also has been based on the observations that happened in the local environment similar to elsewhere. In the meantime, the Department of Meteorology uses scientific methods of forecasting weather as the official weather information provider in Sri Lanka. Studies have shown the use of both systems in Sri Lanka for farming decisions (Berger et al., 2009; Menike and Arachchi, 2016). Empirical studies have found that the weather information is important to improve the climate change adaption of the farmers as a remedial measure for the climate change impact in the long run (Broad et al., 2002; Burton, 2004). In Sri Lankan context also climate change impact has been studied and evidenced by the researchers (Droogers, 2004; Senaratne and Scarborough, 2011; Dharmarathna, 2014; Truelove et al., 2015). However, the use behaviour of weather information and the impact factors have not so far been studied under Sri Lankan context. Therefore, the objective of the research was to study the weather information use behaviour of Sri Lankan paddy farmers in order to provide inputs to make suitable interventions for improvements to this behaviour as a future climate change adaptation strategy.

\section{METHODOLOGY}

Theoretical framework to identify the information use behaviour
The available empirical studies on the valuation of weather information have shown that the difficulty of employing economic models or concepts that are applicable to any other economic good or service. This difficulty is in part due to lack of well-defined use of weather information and exact points of use, intact nature of user and producer, and unorganized nature of weather information products (Yates-Mercer and Bawden, 2002). However, it has been identified that behavioural approaches (especially attitude-based models) which focus on the identification of the determinants of behavioural intention are useful to study the determinants of information use (Burton., 2004).

The theory of panned behaviour (TPB) (Fishbein and Ajzen, 1975; Ajzen and Madden, 1986) has been widely used to demonstrate the human behaviour in both volitional and non-volitional manners (Valle et al., 2005). As per the TPB (Figure 1), intention to perform different behaviours, can be predicted with high accuracy from attitudes, subjective norms, and perceived behavioural control which are called as the constructs (Ajzen, 1991).

According to TPB, the intentions are supposed to capture the motivational factors that influence the behaviour and act as indications of the different levels of actions in order to perform the behaviour. As a rule of thumb, when stronger the intention to engage in a behaviour, the more likely should be its performance (Kaufmann et al., 2009). Subjective norm is defined as the extent of perceived pressure from others to perform the behaviour (Fishbein and Ajzen, 1975). The TPB has considered the person's own attitude which tells about the strong feeling towards the behaviour is important to perform the behaviour (Wicker,1969). The perceived behavioural control is a multidimensional construct which is used to capture the perception of both internal (e.g., knowledge, skills, will-power) and external (e.g., time, opportunity, cooperation of others) factors to the actor (Ajzen, 2005). However, the constructs of the TPB can predict the human behaviour in to a limited extent only. So, the expectancy values are found to be limited and only partly successful in dealing with the real relations (Ajzen, 1991).

As applications of TPB, examination of the combined impact of self-identity and social identity constructs on intention and behaviour, and examination of the effect of self-identity as a function of past experience of performing the behaviour, can be identified (Terry et al., 1999). The TPB has been used as the theoretical framework to study the farmers' behaviour of weather information use, since it is not fully under 
volitional control. For instance, weather information use is influenced by factors like extreme weather events (Tolma et al., 2006; Sharifzadeh et al., 2012).

\section{Data collection and use}

The unit of analysis of the research was individual paddy farmers in Sri Lanka. The multistage random sampling technique was employed to select the sample of farmers. In the first stage, the entire farmer population distributed within the four main climate zones in Sri Lanka was identified according to the irrigation pattern of the paddy cultivation. They are namely, Irrigated paddy farming system in dry zone, rainfed paddy farming system in intermediate zone, rainfed paddy farming system in wet zone and rainfed paddy farming system in the semi-arid regions of Sri Lanka. In the second stage, two villages from each selected district within the each climate zone were considered to carry out the research. In this regard, Anuradhapura, Rathnapura, Badulla, Hambanthota, Kurunegala and Batticaloa districts were selected. Finally, a random sample of paddy farmers was selected from each village to make the whole sample size as 900 . The data collection was carried out in 2016 by using a pretested structured questionnaire.

The literature related to structural equation models (SEMs) have shown arguments regarding the number of items to be used to build a construct. As a rule of thumb, many studies have used minimum amount of items to build a construct in preliminary studies. Not only that due to the administering difficulty of questioners and research management aspects, it has been suggested to use one item only in recent studies to build a construct (Wanous and Reichers, 1996; Drolet and Morrison, 2001; Bergkvist and Rossiter, 2007). Further, it has been proven that the accuracy of using such single constructs not only to measure latent variables like attitude, behaviourand intention but also to use them the in SEMs even with multiple samples (Bergkvist and Rossiter, 2007; Petrescu, 2013). Considering these arguments and the nature of weather information use in Sri Lanka, the study used a single item to build a construct. Therefore, all the constructs were measured by using a single item which had 15 Likert scale and used as the latent variables separately in the two SEMs.

Two SEMs were built by using TPB to study the information use behaviour with respect to available two weather information forecast systems in Sri Lanka (Tolma et al., 2006; Sharifzadeh et al., 2012;). As the dependent variables in the two SEMs representing the behaviour in TPB, the use frequency of scientific weather forecasts on the local media (TV/Radio/ Newspapers) and use frequency of local traditional knowledge were used. Each dependent variable was measured on a scale ranging from 1 to 5 (where 1= Very low, 2 =Low, 3= Moderate, 4=High, $5=$ Very high) using one item. The intention of use was assessed as the

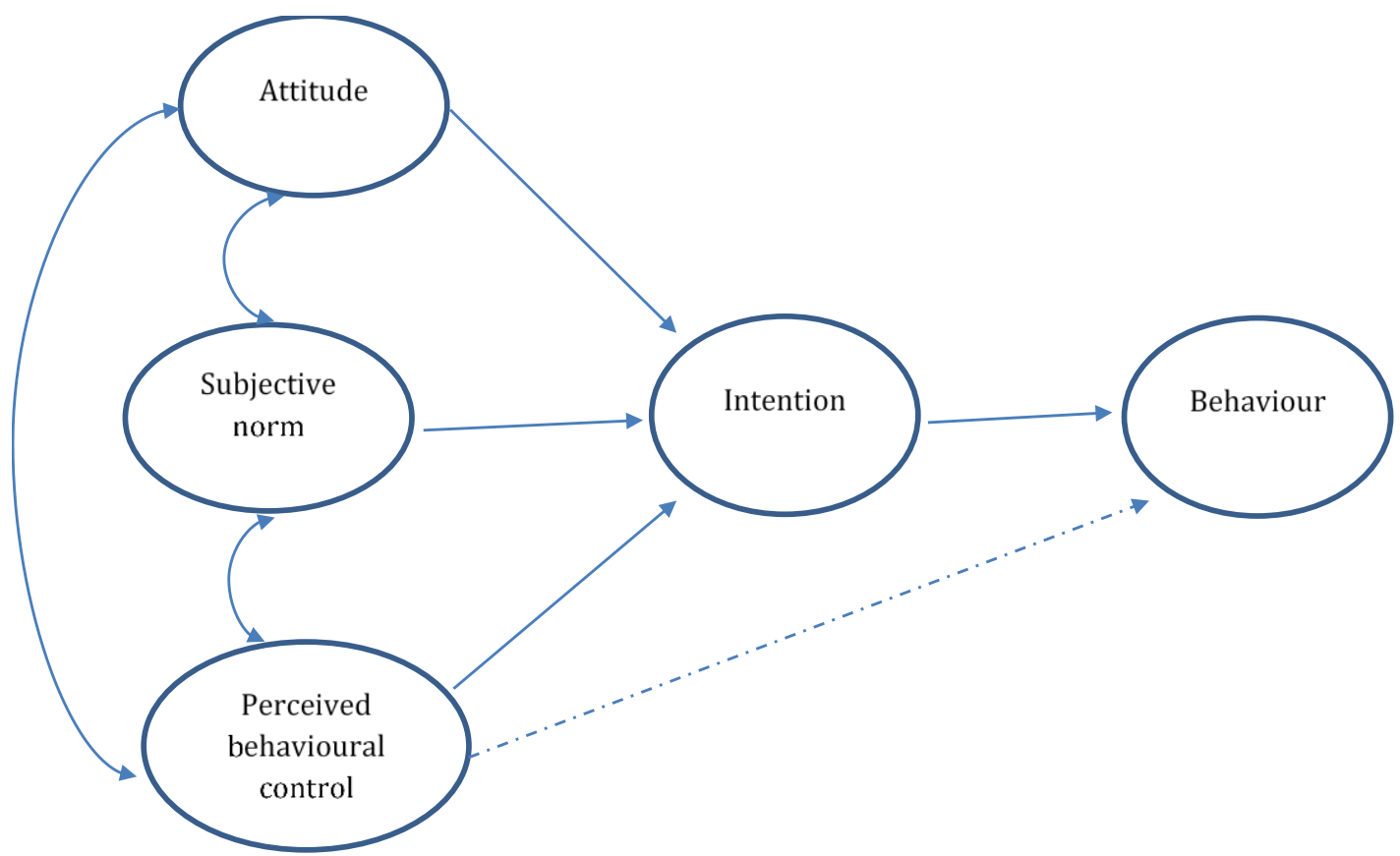

Figure 1: Theory of Planned Behaviour (Source: Ajzen, 1991) 
reliability of information. Because, TPB indicates strong intention makes a high chance to use it again (Fishbein and Ajzen, 1975). Therefore, the intention is the factor that intended to perform "behaviour" over the next farming season. The attitudes toward the use of weather information were measured as the ease of use and usefulness of information (Kraft et al., 2005; Smarkola, 2008). Similarly, the cost effectiveness was used as the measure of ease of use. The farmers' selection of weather information is influenced from various persons/groups like emotional groups and experts (Kraft et al., 2005; Smarkola, 2008). Thus, as the subjective norm for the scientific information use, information from experts was considered. Similarly, for the traditional knowledge use, information from fellow farmers was used. The perceived behavioural control consisted of two sub-constructs. They are perceived difficulty (PD) and perceived control (PC) (Ajzen, 2002). The addition of difficulty level as a perceived behavioural control has been basically considered the specific factors related to the studied area, type of information and source of information (Kraft et al., 2005; $\mathrm{Hu}$ et al., 2006; Smarkola, 2008). Therefore, the perceived behavioural control was considered as the accessibility to the information system. The impact of demographic factors for all the latent independent variables was also measured.

\section{Suitability of Data to Build a Structural Equation Model}

To build a SEM, a high internal consistency which describes the extent of all items in a test measure with the same concept or construct, is required among the responses when it measures directly (Tavakol and Dennick, 2011; Sharifzadeh et al., 2012). The Cronbach's alpha test (Cronbach, 1951) is used to measure the acceptable scale for high consistency where, it expressed as a number between 0 and 1. (Bagozzi and Yi, 1988). However, some studies have pointed out that internal consistency scores are subjective to the study and the nature of the field. Moreover, the low values $(0.50$ and 0.60$)$ can be accepted at the early stages of the research (Nunnally ,1978; Bayraktar et al., 2008). Even though some researchers argue on the validity of a single item scale (Wanous and Hudy, 2001; Fuchs and Diamatopoulos, 2009), others have suggested a single item scale is satisfactory to measure most of the latent variables which usually considered through number of items in early studies after comparing the reliability and accuracy of results in various disciplines (Petrescu, 2013). When it concerns the reliability, the Cronbach's alpha is used for scales which has at least three items as a general rule to see the internal consistency. The other scales that contain two items have been checked for the internal consistency with Spearman - Brown correlation test or Pearson correlation test rather the Cronbach's alpha (Eisinga et al., 2013.). However, it has been shown that the single item scales cannot be tested for internal consistency by any of these three tests (Petrescu , 2013). The available literature suggested few alternations in this context. The statistical corrections like attenuation formula had been used to correct for the reliability (Wanous and Huddy, 2001). Some studies have suggested to use the reliability scores of other studies or suggested to assume the reliability of the single item scale (Jöreskog and Sörbom,1982; MacKenzie, 2001). However, test-re-test reliability method has been suggested to see the consistency of the scales. In this regard, arguments can be found related to the maximum and minimum time lag for the test-re-test, across research fields and research purposes (Mørkbak, and Olsen, 2015). However, it has been mentioned that maximum 6month gap is acceptable generally to test the consistency of the responses. Further, it has found that one-year gap between the tests would reduce the accuracy of the test. By considering all, the reliability of the study was considered through test-retest reliability. The original study (on which this study was based on) was conducted as a baseline line survey. The end survey also used the same questionnaire after a cropping season. Because of this reason, the responses were tested for the test-retest to see the internal consistency.

The sample adequacy was tested with KaiserMeyer-Olkin Test (KMO) (Kaiser, 1970; Williams et al., 2010). The KMO index is recommended when the cases to variable ratio are less than $1: 5$. The KMO index ranges from 0 to 1 , with 0.50 considered suitable for factor analysis (Pallant., 2005; Williams et al., 2010). The sphericity was tested with the Bartlett's test (Bartlett, 1950) which is sensitive to departures from normality (Nielsen, 2002; Handbook of Statistical Methods, 2012).

The confirmatory factor analyses (CFA) are exploratory and partly confirmatory. It means that, the resultant model in a CFA is derived partially by the theory and partially by re-specifications based on the analysis of model fit (Gerbing and Hamilton, 1996). But, the researchers often erroneously assume that CFA is only used to verify or confirm hypothesized models as a must pass test (Schmitt, 2011). However, it has shown that exploratory methods (i.e., principal-axis and maximumlikelihood factor analysis) are able to recover the correct factor model satisfactorily in a majority of the theoretical model based studies even without 
confirmed through a preliminary CFA (Gerbing and Hamilton, 1996; Worthington and Whittaker ,2006). A Confirmatory Factor analysis (CFA) was excluded in this study, since this study is based on already widely used TPB.

\section{Structural Equation Model}

Two SEMs were built by using STATA 14 software. In diagrams, arrows symbolize direct effects. The measured or observed variables are symbolized as rectangles and the measurement errors (associated with rectangles) are symbolized as circles. The latent variables are symbolized as the oval shape and the errors (associated with ovals) as circles. The curves symbolised covariance. The numbers appear above the rectangles and ovals show the explained variances of the variables (indicator reliability). The numbers close to the arrows show the standardized regression coefficients of each causal relationship (Stata guide, 2011; Sharifzadeh et al., 2012).

\section{Evaluation of Structural Equation Model}

The evaluation of the fit of a hypothesized model is crucial and a key feature of SEM (Parry, 2017; Rex, 2005). The model Chi-square tests the overall fit and the difference between the sample and fitted covariance matrices. ( $\mathrm{H}_{0}$ : The model fits perfectly). This is tested with the $p>0.05$ (Parry, 2017). Under likelihood ratio in STATA output reports two tests for saturated model versus restricted model and baseline model versus saturated model. The saturated model is the model that fits the covariance perfectly. The rejection can be performed at the 5\% level (or any other level) that the selected model fits as well as the saturated model. It indicates at $p>0.05$, reject the null hypothesis and accept the saturated model as the best model over the restricted model (the model with the minimum number of variables: the used model in the study). The second test is a comparison of baseline model versus saturated. The baseline model includes the mean and variances of all observed variables plus the covariance of all observed exogenous variables. The rejection can be done at the 5\% level (or any other level) (STATA guide, 2011).

The Tucker-Lewis Index (TLI) indicates the model of interest improves the fit by $95 \%$ relative to the null model. This TLI is preferred to $>=0.95$. The Comparative Fit Index (CFI) Compares the fit of a target model to the fit of an independent, or null model. This CFI is preferred to $>=0.90$ (Parry, 2017). Root Mean Square Error Approximation (RMSEA) values closer to 0 is accepted as a good fit. The cut-off value would be, RMSEA $<0.08$ (Parry,
2017). However, in STATA output, the RMSEA value is reported along with both lower and upper bounds as at $90 \%$ confidence interval. If the lower bound is below 0.05 , then it would not reject the hypothesis that the fit is close. If the upper bound is above 0.10 , it would not reject the hypothesis that the fit is poor. The p-close, is also used along with RMSEA which is the probability that the RMSEA value is less than 0.05 . It is interpreted as the probability that the predicted moments are close to the moments or gives a test of close fit while $p$ gives a test of exact fit in the population. (Chen et al., 2008). The Standardized Root Mean Squared Residual (SRMR) considered the difference between the residuals of the sample covariance matrix and the hypothesized model. If the variables vary in range (i.e. some variables are 1-5, others 1-7) then Root Mean Squared Residual [RMR] is hard to interpret, hence use SRMR. A perfect fit corresponds to SRMR equals to 0 , and a good fit corresponds to small values. The cutoff considered to be limited at SRMR $<0.08$ (Parry, 2017). Coefficient of Determination (CD) acts as like an $\mathrm{R}^{2}$ for the whole model. A value close to 1 indicates a good fit (Stata guide., 2011)

\section{RESULTS AND DISCUSSION}

The male representation of the respondents was $80.22 \%$. The average age of respondents was $56 \pm 13.2$ years. Farming experience was $26 \pm 14.5$ years. The level of education was found as, No schooling $3 \%$; primary education $32 \%$, secondary education $55.5 \%$ and tertiary education or above $9.44 \%$. Farming was the main occupation of $96.63 \%$ of the respondents. The average paddy cultivation was $2.69 \pm 4.93$ acres in Yala season in 2015 and $2.32 \pm 2.61$ acres in in Maha season in 2015. Climate change has been recognized as a risk by farmers as, low risk by $10.67 \%$, medium risk by $27.33 \%$ and as a high risk by $62 \%$. Sources of weather information of and their use by respondents has been shown in Table 1 .

The test-retest showed a poor correlation between the constructs which was used to capture the same latent variables in two different times. However, some constructs like frequency of scientific information use which used as the dependent variable of the scientific information use model had statistical significance $(p<0.05)$ in between the single item scales in the two surveys, even though the correlation is poor. However, the poor correlation can be justified as per the literature due to the time gap between the two seasons. 
Table 1: User perception about the two weather information sources

\begin{tabular}{|c|c|c|c|c|c|c|c|c|c|c|c|}
\hline \multirow{2}{*}{ Source } & \multirow{2}{*}{ Event } & \multicolumn{2}{|c|}{ Very low } & \multicolumn{2}{|c|}{ Low } & \multicolumn{2}{|c|}{ Moderate } & \multicolumn{2}{|c|}{ High } & \multicolumn{2}{|c|}{ Very high } \\
\hline & & Count & $\%$ & Count & $\%$ & Count & $\%$ & Count & $\%$ & Count & $\%$ \\
\hline Weather reports & Frequency of use & 286 & 31.78 & 190 & 21.11 & 332 & 36.89 & 72 & 8.00 & 20 & 2.22 \\
\hline \multirow[t]{3}{*}{ (TV/Radio/ Newspaper) } & Reliability & 220 & 24.44 & 200 & 22.22 & 377 & 41.89 & 84 & 9.33 & 19 & 2.11 \\
\hline & Accessibility & 131 & 14.56 & 158 & 17.56 & 319 & 35.44 & 216 & 24.00 & 76 & 8.44 \\
\hline & Cost effectiveness & 160 & 17.78 & 183 & 20.33 & 371 & 41.22 & 170 & 18.89 & 16 & 1.78 \\
\hline \multirow[t]{4}{*}{ local observation } & Frequency of use & 76 & 8.85 & 76 & 8.85 & 320 & 37.25 & 301 & 35.04 & 86 & 10.01 \\
\hline & Reliability & 586 & 68.38 & 119 & 13.89 & 109 & 12.72 & 33 & 3.85 & 10 & 1.17 \\
\hline & Accessibility & 49 & 5.81 & 74 & 8.77 & 309 & 36.61 & 314 & 37.20 & 98 & 11.61 \\
\hline & Cost effectiveness & 54 & 6.45 & 94 & 11.23 & 328 & 39.19 & 290 & 34.65 & 71 & 8.48 \\
\hline
\end{tabular}


In this regard, the two surveys had more than 6month gap between the considered cropping seasons which lead to poor correlation between the scales. Therefore, it was observed that analysing the internal consistency of a single scale by employing the test-retest is difficult, especially in a seasonal study. The KMO test was used to measure the sampling adequacy which indicates that the sample size is large enough to assess the factor structure. The KMO value for each construct was above 0.6 with a significant Bartlett's test of sphericity value, indicating that the data were sufficient to proceed for the SEM analysis. Bartlett's Test of Sphericity (BTS) was significant at $\alpha<0.05$, therefore, factorability of the correlation matrixes was assumed. In this regard, the degree of freedom was 10 in both sets of constructs considered. The constructs used for scientific information use had a chi-square value of $106.93(\mathrm{p}<0.05)$ and constructs used for local weather information had a chisquare value $1813.00(\mathrm{p}<0.05)$ for Bartlett's Test of Sphericity. The KMO values were 0.75 for the constructs related scientific information use and 0.84 for the constructs related local weather information use.

To select the best fitted SEM to reveal each information system use behaviour, a series of structural equation path models were tested. In this regard, a SEM to determine the adequacy of the theory of planned behaviour in explaining the
Table 2: Results of the sample adequacy tests conducted for the variables related to scientific weather information use and local weather information use.

\begin{tabular}{llcc}
\hline Test & Statistic & $\begin{array}{c}\text { Value for } \\
\text { scientific } \\
\text { information } \\
\text { use }\end{array}$ & $\begin{array}{c}\text { Value for } \\
\text { local } \\
\text { information } \\
\text { use }\end{array}$ \\
\hline BTS & $\begin{array}{l}\text { Approx. } \\
\text { Chi- }\end{array}$ & 106.93 & 1813.00 \\
& Square & & \\
KM0 & Value & 0.75 & 0.84 \\
& df & 10 & 10 \\
& p value & $<0.05$ & $<0.05$ \\
\hline
\end{tabular}

weather information use behaviour without casual paths in between the constructs was tested at first. But the goodness of fit was $p<0.05$ for the both weather information systems. Therefore, as a solution to this the direct causal paths in between constructs were added and dropped until it improves the goodness of fit statistics and significantly different for the both SEMs of two weather information systems. This method has been used in psychology researches to select the best fitted model when performing CFA (Doris et al., 2012) and SEMs (Sharifzadeh et al., 2012). Table 3 showed the goodness of fit of the models.

Table 3: Goodness of fit of the selected SEMs for the two information use behaviours

\begin{tabular}{|c|c|c|c|}
\hline Fit statistics & $\begin{array}{c}\text { Value for } \\
\text { Scientific } \\
\text { information use } \\
\end{array}$ & $\begin{array}{c}\text { Value for } \\
\text { local } \\
\text { information use }\end{array}$ & Description \\
\hline \multicolumn{4}{|l|}{ Like hood ratio: } \\
\hline Chi- square & 19.51 & 16.69 & Model vs. Saturated \\
\hline p> chi-square & 0.053 & 0.054 & \\
\hline \multicolumn{4}{|l|}{ Population error: } \\
\hline RMSEA & 0.03 & 0.032 & $\begin{array}{l}\text { Root Mean Squared Error of } \\
\text { Approximation }\end{array}$ \\
\hline $90 \% \mathrm{CI}$, lower bound & 0.000 & 0.000 & \\
\hline Upper bound & 0.051 & 0.056 & \\
\hline $\mathrm{p}$-close & 0.940 & 0.877 & Probability RMSEA <= 0.05 \\
\hline \multicolumn{4}{|l|}{ Information criteria: } \\
\hline AIC & 47751.4 & 43376.6 & Akaike's information criterion \\
\hline $\mathrm{BIC}$ & 47913.6 & 43545.9 & Bayesian information criterion \\
\hline \multicolumn{4}{|l|}{ Baseline comparison: } \\
\hline CFI & 0.992 & 0.996 & Comparative fit index \\
\hline TLI & 0.975 & 0.984 & Turker-Lewis index \\
\hline \multicolumn{4}{|l|}{ Size of residuals: } \\
\hline SRMR & 0.016 & 0.021 & $\begin{array}{l}\text { Standardized root mean } \\
\text { squared residual }\end{array}$ \\
\hline CD & 0.09 & 0.041 & Coefficient of determination \\
\hline
\end{tabular}


Table 4: The impact of the demographic factors on each latent variable in the two SEMs

\begin{tabular}{lcccc}
\hline \multirow{2}{*}{ Construct } & \multicolumn{2}{c}{$\begin{array}{c}\text { SEM for local } \\
\text { weather information use }\end{array}$} & \multicolumn{2}{c}{$\begin{array}{c}\text { SEM for scientific } \\
\text { information use }\end{array}$} \\
\cline { 2 - 5 } & Coefficient & $\mathbf{p}$ & Coefficient & P \\
\hline Attitude: & & & & \\
$\quad$ Climate risk perception & 0.127 & $0.018^{*}$ & $\mathrm{NA}$ & $\mathrm{NA}$ \\
Farming experience & -0.007 & 0.685 & -0.005 & $0.016^{*}$ \\
$\quad$ Education & 0.016 & 0.565 & 0.0345 & 0.371 \\
$\quad$ Gender & -0.414 & 0.516 & -0.148 & $0.055^{* *}$ \\
Income & $2.40 \mathrm{e}-07$ & $0.093^{* *}$ & $3.80 \mathrm{e}-07$ & $0.014^{*}$ \\
Subjective Norm: & & & & \\
Income & $\mathrm{NA}$ & $\mathrm{NA}$ & $\mathrm{NA}$ & $\mathrm{NA}$ \\
$\quad$ Gender & -0.14 & $0.091^{* *}$ & -.114 & 0.122 \\
Education & 0.059 & $0.098^{* *}$ & $\mathrm{NA}$ & $\mathrm{NA}$ \\
Farming Experience & -0.001 & 0.935 & -0.005 & $0.003^{*}$ \\
$\quad$ Climate risk perception & 0.113 & $0.031^{*}$ & -0.005 & $0.075^{* *}$ \\
Planned behavioural control: & & & & \\
Education & $\mathrm{NA}$ & $\mathrm{NA}$ & 0.0969 & $0.023^{*}$ \\
Income & $3.98 \mathrm{e}-07$ & $0.001^{*}$ & $4.64 \mathrm{e}-07$ & $0.007^{*}$ \\
$\quad$ Climate risk perception & 0.182 & $0.005^{*}$ & 0.274 & $0.000^{*}$ \\
Intention: & & & & \\
Income & $1.38 \mathrm{e}-07$ & 0.177 & $\mathrm{NA}$ & $\mathrm{NA}$ \\
Gender & 0.081 & 0.180 & -0.114 & 0.122 \\
Education & 0.006 & 0.796 & $\mathrm{NA}$ & $\mathrm{NA}$ \\
Farming Experience & 0.002 & 0.173 & -0.005 & $0.003^{*}$ \\
Climate risk perception & -0.022 & 0.543 & -0.081 & $0.075^{* *}$ \\
\hline
\end{tabular}

${ }^{*} \mathrm{p}<0.05,{ }^{* *} \mathrm{p}<0.1$

According to the SEMs, two diagrams (Figure 2 and 3) have been developed by using SEM builder of STATA 14. According to Figure 2, the results revealed that $70 \%$ of the variance is associated with the scientific weather information use behaviour while predicting with the considered four constructs. Therefore, the model can only predict the behaviour with $30 \%$ accuracy. Further, the SEM showed significant relationships between the variables as per the Figure 2 where, (1) attitude and intention $(\beta=0.41, p<0.05),(2)$ attitude and behaviour $(\beta=0.22, p<0.05$. (3) subjective norm and intention $(\beta=0.11, p<0.05),(4)$ perceived behavioural control and intention $(\beta=0.13$, $\mathrm{p}<0.05),(5)$ intention and behaviour $(\beta=0.45$, $\mathrm{p}<0.05$ ). The three predictor variables (attitude, subjective norm and perceived behavioural control) and demographic variables (climate risk perception, gender and farming experience) explained $75 \%$ of the variance in the intention.

The squared multiple correlations were examined to determine the proportion of variance that was explained by the exogenous constructs in the theoretical model. This step was carried out to observe the direction, significance, and magnitude of the paths corresponding to each hypothesis of the theoretical model. Results revealed that the 'attitudes' had the highest standardized effect (regression coefficients, $\beta=0.41, \quad \mathrm{p}<0.05$ ) on intention toward scientific weather information use followed by 'subjective norms' $\quad(\beta=0.11$, $\mathrm{p}<0.05)$. The findings were similar with the previous research findings (Sharifzadeh et al., 2012). The effect of intention on scientific weather information use was relatively high $(\beta=0.45$, $\mathrm{P}<0.05)$ and followed by the attitude $(\beta=0.22$, $\mathrm{p}<0.05$ ). Similarly, the results (Figure 3) revealed that $51 \%$ of the variance is associated with local weather information use with the considered four factors. Further, the SEM model showed significant relationships between the variables: (1) attitude and intention $(\beta=0.40, P<0.05),(2)$ attitude and behaviour $(\beta=0.21, p)$. (3) Subjective norm and intention $(\beta=0.05, \quad P<0.05), \quad(4)$ perceived behavioural control and intention $(\beta=0.36$, $\mathrm{P}<0.05),(5)$ intention and behaviour $(\beta=0.42$, $\mathrm{P}<0.05$ ). The three predictor variables (attitude, subjective norm and perceived behavioural control) and demographic variables explained 46 $\%$ of the variance in the intention. The squared multiple correlations were also examined in this model to determine the proportion of variance that was explained by the exogenous constructs in the theoretical model. 


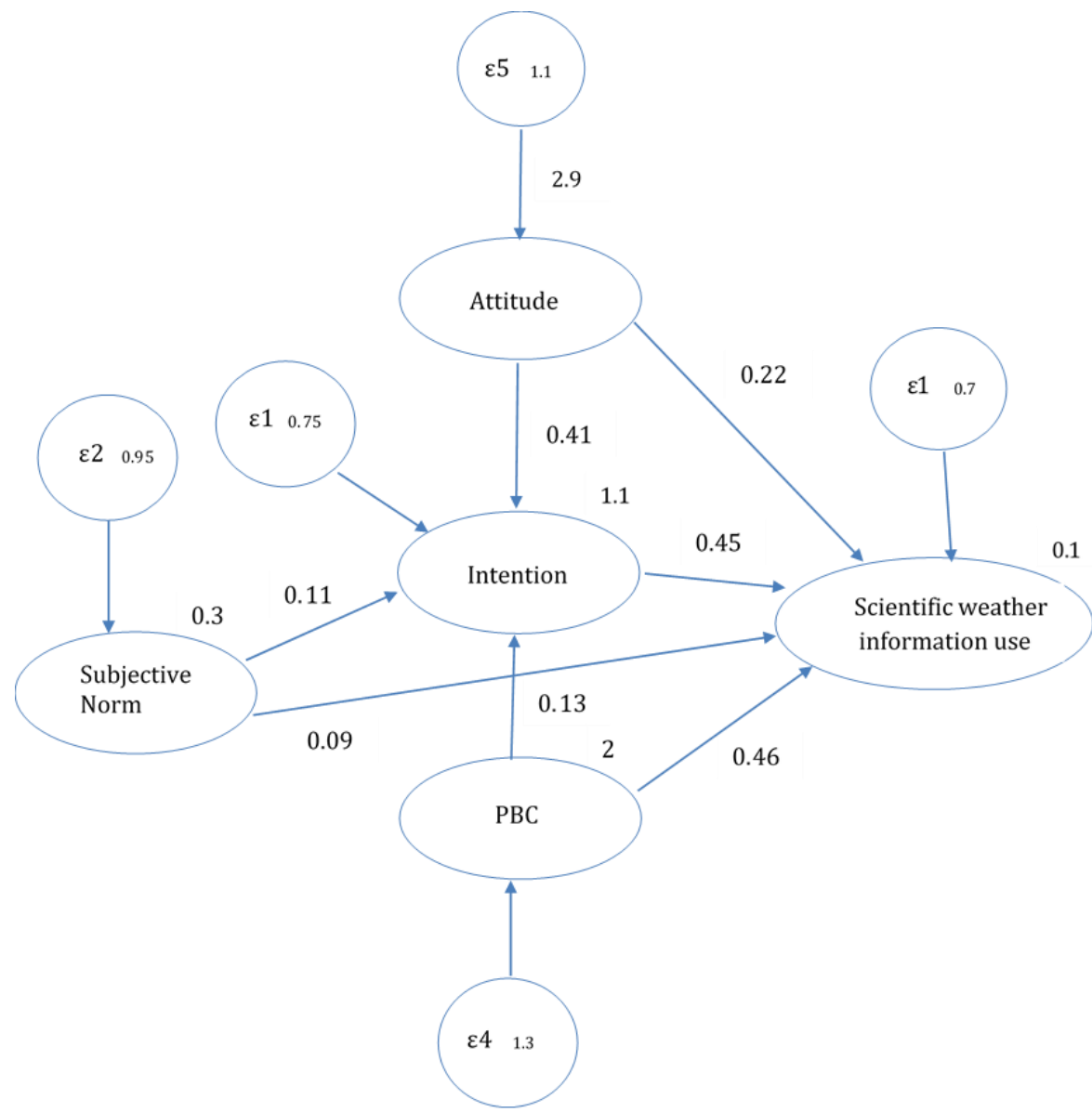

Figure 2: SEM for the scientific weather information use (please see the text for details)

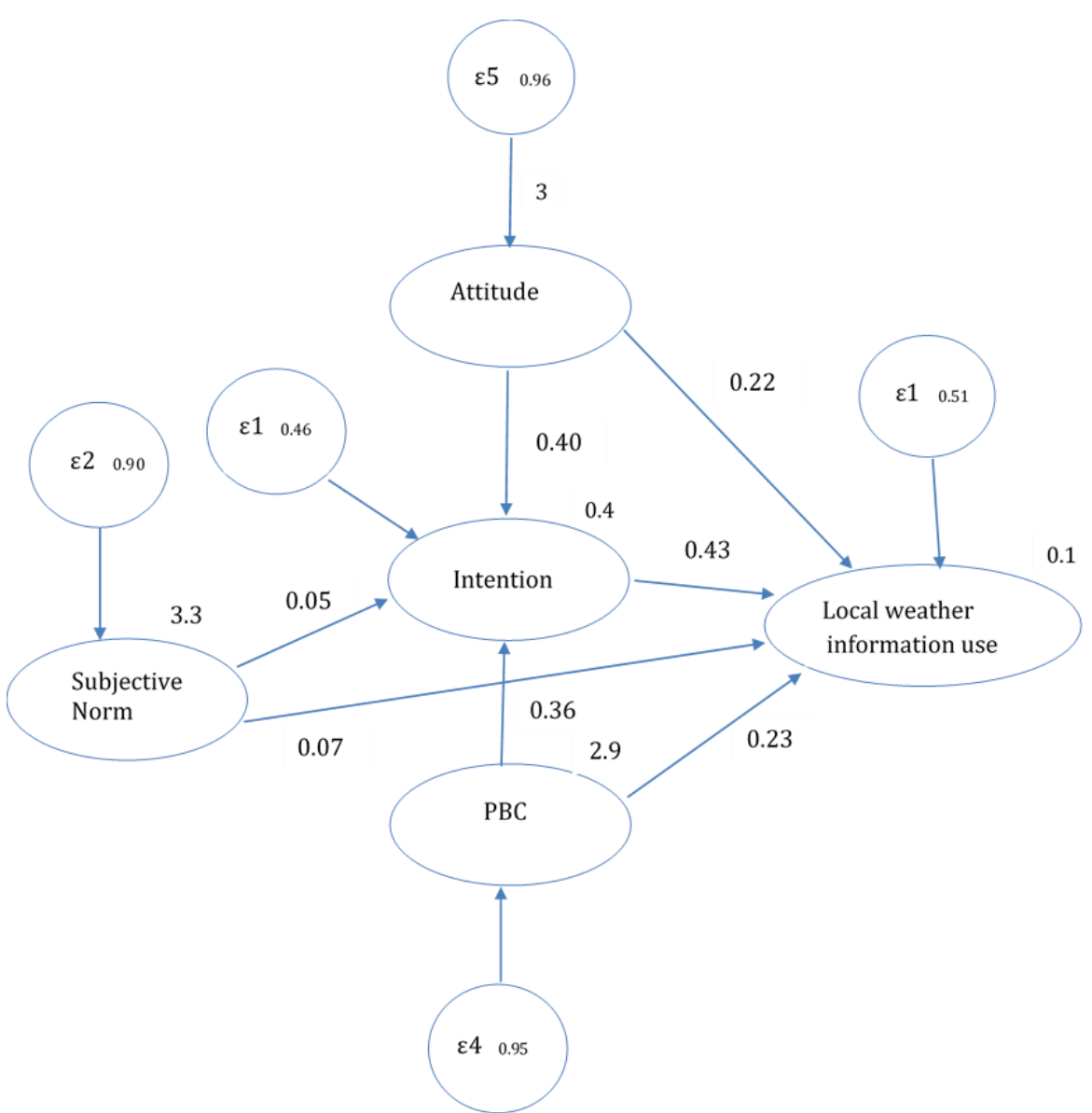

Figure 3: SEM for the local weather information use (please see the text for details) 
Results revealed that the attitudes had the highest standardized effect $(\beta=0.40, \mathrm{P}<0.05)$ on intention toward local weather information use followed by PBC $(\beta=0.36, P<0.05)$. The effect of Intention on local weather information use was relatively high $(\beta=0.43, \mathrm{P}<0.05)$ followed by attitudes $(\beta=0.23$, $\mathrm{P}<0.05)$. The impact of the demographic factors for each latent variable and the related significance levels have been shown in the Table 4 .

The SEMs based on the TPB can be used to study the weather information use behaviour of Sri Lankan farmers to estimate the multiple dependence relationships. Similar findings have been reported by others (Valle et al., 2005; Sharifzadeh et al., 2012). However, the latent variables have been considered here in a single item scale. The undergone reason was, the weather information has a ubiquitous nature and no specific cost or adoption requirements. Farmers in Sri Lanka have various views on weather information based on their experiences and uses. The volitional behaviour of farmers is expected according to their knowledge and perception. In-depth views on general things cannot be obtained from every respondent easily. So, research management becomes hard in such situations. Further, weather information products or packages are not available to farmers. As a result, inquiring the various attributes regarding such abstract information seemed as difficult to respond. Such issues have been found and highlighted as a barrier to build a multidimensional scale. As an example, it requires additional time and effort to take similar responses for all the constructs (Blasco et al., 2011). And also, the validation of the internal consistency by employing test-retest method is not practical unless it completed with the questionnaire pre testing stages. However, the long duration would reduce the internal consistency especially even the same questionnaire was used in the end surveys. As revealed by the study, the behaviour-specific beliefs were stronger predictors of intention related to the both weather information systems. The demographic variables and other psychological variables, such as risk perceptions are contributed to the behaviour specific beliefs. These findings were similar to the available results of other behavioural studies which conceptually follow the TPB (e.g., health behaviour, environmental conservation, recycling behaviour and agricultural information use behaviour) (Mathieson, 1991; Burton, 2004; Valle et al., 2005).

\section{CONCLUSIONS}

The study concludes that, the SEMs based on the TPB can be used to study the weather information use behaviour of Sri Lankan farmers to estimate the multiple dependence relationships. However, issues such as ubiquitous nature of weather information, difficulty in obtaining in-depth views from farmers, volitional behaviour of the farmers, and unavailability of weather information products have been found and highlighted as a barrier to build a multidimensional scale. The behaviourspecific beliefs were stronger predictors of intention related to the both weather information systems studied. The demographic variables and other psychological variables, such as risk perceptions contributed to the behaviour specific beliefs that are important to capture when promoting or introducing of weather information products or to understand the existing weather information use.

\section{Policy implication}

The most frequently used weather information source as the behaviour of information use of the studied Sri Lankan paddy farmers, was local weather information sources over the scientific weather information. The information use behaviour has been impacted attitude, intention, perceived behaviour control and subjective norm with respect to both information sources. The expected turbulences in the future climate due to human induced global warming will impact on the success of the local weather predictions and the accuracy. Therefore, the use of scientific weather information should be promoted among the farmers. Since, it is important to improve the strength of behavioural beliefs of farmers on the scientific weather information sources, the extension programmes and awareness campaigns are needed to be designed to intervene the existing behavioural beliefs to support the use behaviour of scientific weather information while providing scientific weather information through dissemination channels. As an example to promote the scientific weather information use, it needs to capture the behavioural components which could contribute to reduce the local weather information use and those which promote the of scientific weather information use.

\section{ACKNOWLEDGEMENT}

The data were collected while the corresponding author was affiliated with the Institute of Policy Studies of Sri Lanka (IPS) as a project officer. The corresponding author would like to thank the Environmental Economic Policy Division of IPS for permitting to use the data for the study. 


\section{REFERENCES}

Ajzen, I. (2005). Attitudes, Personality, and Behavior. McGraw-Hill Education, UK. pp.

Ajzen, I. (1991). The theory of planned behavior. Organizational Behavior and Human Decision Processes, 50(1), 179-211.

Ajzen, I .( 2002). Constructing a TPB questionnaire: Conceptual and methodological considerations.

Ajzen, I. and Madden, T.J. (1986). Prediction of goal-directed behavior-attitudes, intentions, and perceived behavioral-control. Journal of Experimental Social Psychology, 22(5), 453474.

Bagozzi, R.P. and Yi, Y. (1988). On the evaluation of structural equation models. Journal of the Academy of Marketing Science, 16(1), 74-94.

Bayraktar, E., Tatoglu, E. and Zaim, S. (2008). An instrument for measuring the critical factors of TQM in Turkish higher education. Total Quality Management, 19(6), 551-574.

Bartlett, M.S., 1950. Tests of significance in factor analysis. British Journal of Statistical Psychology, 3(2), 77-85.

Berger, R., Weregoda, R. and Rathnabharathie, V. (2009). Participatory rice variety selection in Sri Lanka. Participatory Learning and Action, 60(1), 88-98.

Bergkvist, L. and Rossiter, J.R. (2007). The predictive validity of multiple-item versus single-item measures of the same constructs. Journal of Marketing Research, 44(2),175-184.

Broad, K, Alexander S.P, and Michael H. G.(2002) "Effective and equitable dissemination of seasonal-to-interannual climate forecasts: policy implications from the Peruvian fishery during El Nino 1997-98." Climatic Change 5(4), 415-438

Blasco, M.F., Saura, I.G., Contri, G.B. and Velazquez, B.M. (2011). Measuring multidimensional eservice quality and its impact on customer perceived value and loyalty. Journal of Marketing Trends 1(6), 23-34.
Burton, R.J. (2004). Reconceptualising the behavioural approach in agricultural studies: a socio-psychological perspective. Journal of Rural Studies, 20(3), 359-371.

Chen, F., Curran, P.J., Bollen, K.A., Kirby, J. and Paxton, P. (2008). An empirical evaluation of the use of fixed cutoff points in RMSEA test statistic in structural equation models. Sociological Methods \& Research, 36(4), 462494.

Cronbach, L.J., (1951). Coefficient alpha and the internal structure of tests. Psychometrika, 16(3), 297-334.

Dharmarathna, W.R.S.S., Herath, S. and Weerakoon, S.B. (2014). Changing the planting date as a climate change adaptation strategy for rice production in Kurunegala district, Sri Lanka. Sustainability Science, 9(1),103-111.

Dorris C, Lim, K.M., Chong, S. and Wong, A.F. (2012). A confirmatory factor analytic approach on perceptions of knowledge and skills in teaching (PKST). Psychological Reports,110 (2),589597.

Drolet, A.L. and Morrison, D.G. (2001). Do we really need multiple-item measures in service research? Journal of Service Research,3(3), 196-204.

Droogers, P. (2004). Adaptation to climate change to enhance food security and preserve environmental quality: example for southern Sri Lanka. Agricultural Water Management, 66(1), 15-33.

Ensor, J. and Berger, R. (2009). Understanding climate change adaptation. Lessons from community based approaches. Warwickshire: Practical Action Publishing.

Eisinga, R., Te Grotenhuis, M. and Pelzer, B. (2013). The reliability of a two-item scale: Pearson, Cronbach, or Spearman-Brown?. International Journal of Public Health, 58(4)6, 37-642.

Fishbein, M. and Ajzen, I. (1975) Belief, Attitude, Intention and Behavior: An Introduction to Theory and Research.

Fuchs, C. and Diamantopoulos, A. (2009). Using single-item measures for construct measurement in management research: 
Conceptual issues and application guidelines. Die Betriebswirtschaft, 69(2), 195.

Joreskog, K.G. and Sorbom, D. (1982) Recent developments in structural equation modeling. Journal of Marketing Research 19 (4), 404-416.

Gerbing, D.W. and Hamilton, J.G. (1996). Viability of exploratory factor analysis as a precursor to confirmatory factor analysis. Structural Equation Modeling: A Multidisciplinary Journal, $3(1), 62-72$.

Giorgi, F., Jones, C. and Asrar , G.R. (2009). Addressing climate information needs at the regional level: the CORDEX framework. World Meteorological Organization (WMO) Bulletin, 58(3), 175 .

Hu, Q., Zillig, L.M.P., Lynne, G.D., Tomkins, A.J., Waltman, W.J., Hayes, M.J., Hubbard, K.G., Artikov, I., Hoffman, S.J. and Wilhite, D.A. (2006). Understanding farmers' forecast use from their beliefs, values, social norms, and perceived obstacles. Journal of Applied Meteorology and Climatology, 45(9), 11901201.

Kaiser, H.F. (1970). A second generation little jiffy. Psychometrika, 35(4), 401-415.

Kalanda-Joshua, M., Ngongondo, C., Chipeta, L. and Mpembeka, F. (2011). Integrating indigenous knowledge with conventional science: Enhancing localised climate and weather forecasts in Nessa, Mulanje, Malawi. Physics and Chemistry of the Earth, Parts A/B/C, 36(1415), 996-1003.

Kraft, P., Rise, J., Sutton, S. and Røysamb, E. (2005). Perceived difficulty in the theory of planned behaviour: Perceived behavioural control or affective attitude? British Journal of Social Psychology, 44(3), 479-496.

Kaufmann, P., Stagl, S. and Franks, D.W. (2009). Simulating the diffusion of organic farming practices in two new EU member states. Ecological Economics,.68(10), 2580-2593.

Luseno, W.K., McPeak, J.G., Barrett, C.B., Little, P.D. and Gebru, G. 2003. Assessing the value of climate forecast information for pastoralists: Evidence from Southern Ethiopia and Northern Kenya. World Development, 31(9), 1477-1494.
MacKenzie, S.B. (2001) Opportunities for improving consumer research through latent variable structural equation modeling. The Journal of Consumer Research 28 (1), 159-166.

Mathieson, K. (1991). Predicting user intentions: comparing the technology acceptance model with the theory of planned behavior. Information Systems Research, 2(3), 173-191.

Menike, L.M.C.S. and Arachchi, K.A.G.P.K. (2016). Adaptation to climate change by smallholder farmers in rural communities: Evidence from Sri Lanka. Procedia Food Science, 288-292.

Mørkbak, M.R. and Olsen, S.B. (2015). A withinsample investigation of test-retest reliability in choice experiment surveys with real economic incentives. Australian Journal of Agricultural and Resource Economics, 59(3), 375-392

Nunnally, J.C. (1978). Psychometric Theory, 2nd ed. New York, McGraw-Hill.

Nielsen,B. ((2002). Bartlett correction of the unit root test in autoregressive models, Biometrika, Volume $\quad 84 \quad$ (2), 500-504. https://doi.org/10.1093/biomet/84.2.500

NIST/SEMATECH. (2012). e-Handbook of Statistical Methods, Publisher? pp. ?[Accessed on 21.07.2020] available at. http://www.itl.nist.gov/div898/ handbook/

Nyong, A., Adesina, F. and Elasha, B.O. 2007. The value of indigenous knowledge in climate change mitigation and adaptation strategies in the African Sahel. Mitigation and Adaptation Strategies for Global Change, 12(5), 787-797.

Orlove, B., Roncoli, C., Kabugo, M. and Majugu, A. (2010). Indigenous climate knowledge in southern Uganda: the multiple components of a dynamic regional system. Climatic Change, $100(2), 243-265$

Pallant, J. (2005). SPSS Survival Manual. A Step By Step Guide to Data Analysis Using SPSS for Windows. Version 12, Open University Press, Berkshire.

Parry, S. (2017). Fit Statistics commonly reported for CFA and SEM. Cornell Statistical Consulting Unit: Cornell University. 
Petrescu, M (2013). Marketing research using single-item indicators in structural equation models. Journal of Marketing Analytics, 1(2), 99-117.

Rex B. Kline. (2005). Principles and Practice of Structural Equation Modeling.

Salinger, M.J., Stigter, C.J. and Das, H.P.( 2000). Agrometeorological adaptation strategies to increasing climate variability and climate change. Agricultural and Forest Meteorology, 103(1-2), 167-184.

Senanayake, S.G.J.N. (2006). Indigenous knowledge as a key to sustainable development.

Senaratne, A. and Scarborough, H. (2011). Coping with climatic variability by rain-fed farmers in dry Zone, Sri Lanka: towards understanding adaptation to climate change, (No. 422-201626917).

Sharifzadeh, M., Zamani, G.H., Khalili, D. and Karami, E. (2012). Agricultural climate information use: an application of the planned behaviour theory. Journal of Agricultural Science and Technology, 14(3), 479-492.

Schmitt, T.A. (2011). Current methodological considerations in exploratory and confirmatory factor analysis. Journal of Psychoeducational Assessment, 29(4), 304-321.

Smarkola, C. (2008). Efficacy of a planned behavior model: Beliefs that contribute to computer usage intentions of student teachers and experienced teachers. Computers in Human Behavior, 24(3), 1196-1215

Stata, A. (2011). STATA Structural Equation Modeling Reference Manual Release 13.

Stigter, C.J., Dawei, Z., Onyewotu, L.O.Z. and Xurong, M.(2005). Using traditional methods and indigenous technologies for coping with climate variability. pp. In: (Eds.) Increasing Climate Variability and Change, Springer, Dordrecht.

Tavakol, M. and Dennick, R. (2011). Making sense of Cronbach's alpha. International Journal of Medical Education

Tolma, E.L., Reininger, B.M., Evans, A. and Ureda, J. (2006). Examining the theory of planned behavior and the construct of self-efficacy to predict mammography intention. Health Education \& Behavior, 33(2), 233-251.

Terry, D.J., Hogg, M.A. and White, K.M. (1999). The theory of planned behaviour: self-identity, social identity and group norms. British Journal of Social Psychology, 38(3), 225-244.

Truelove, H.B., Carrico, A.R. and Thabrew, L. (2015). A socio-psychological model for analyzing climate change adaptation: A case study of Sri Lankan paddy farmers. Global Environmental Change, 31, 85-97.

Valle, P.O.D., Rebelo, E., Reis, E. and Menezes, J. (2005). Combining behavioral theories to predict recycling involvement. Environment and behavior, 37(3), 364-396.

Wagachchi, H.R. and Wiersum, K.F. (1996). Water management in agroforestry systems: integrated buffalo ponds and forest gardens in the Badulla district, Sri Lanka. Agroforestry Systems, 35(3), 291-302.

Wanous, J.P. and Reichers, A.E. (1996). Estimating the reliability of a single-item measure. Psychological Reports, 78(2), 631-634.

Wanous, J.P. and Hudy, M.J. (2001). Single-item reliability: A replication and extension. Organizational Research Methods, 4(4):361375.

Wicker, A.W.(1969). Attitudes versus actions: The relationship of verbal and overt behavioral responses to attitude objects. Journal of Social issues, 25(4), 41-78.

Williams, B., Onsman, A. and Brown, T.(2010). Exploratory factor analysis: A five-step guide for novices. Australasian Journal of Paramedicine, 8(3).

Worthington, R.L. and Whittaker, T.A. (2006). Scale development research: A content analysis and recommendations for best practices. The Counselling Psychologist, 34(6), 806-838.

Yates-Mercer, P. and Bawden, D. (2002). Managing the paradox: the valuation of knowledge and knowledge management. Journal of Information Science, 28(1), 19-29. 